\title{
A Clinic-Epidemilogical Study of Cases of Locally Advanced Non Small Cell Lung Cancer (NSCLC) That Received Radiotherapy at NCI Cairo in the Period from 2001-2010
}

\author{
Mohamed Lotayef ${ }^{1}$, Azza Taher1, Hanna Attia², Azza Nasr'1, Hisham El Hossieny', \\ Mohammed Mahmoud ${ }^{1 *}$, Noha Essam ${ }^{1}$ \\ ${ }^{1}$ Radiation Oncology Department, National Cancer Institute, Cairo University, Cairo, Egypt \\ ${ }^{2}$ Clinical Oncology Department, Faculty of medicine, Cairo University, Cairo, Egypt \\ Email: ${ }^{\text {m m mahmoud1973@yahoo.com }}$
}

Received 8 March 2014; revised 5 April 2014; accepted 12 April 2014

Copyright (C) 2014 by authors and Scientific Research Publishing Inc.

This work is licensed under the Creative Commons Attribution International License (CC BY).

http://creativecommons.org/licenses/by/4.0/

c) (i) Open Access

\section{Abstract}

Purpose: This work was to study the clinic-epidemiological characteristics of patients with locally advanced NCSLC and to analyze their prognostic factors and also the results of different treatment modalities for local control and their effect on overall survival (OAS). Materials and Methods: This is a retrospective study including 121 patients with primary locally advanced NSCLC diagnosed between 2001 and 2010 at the radiotherapy department, National Cancer Institute, Cairo University, Egypt. Results: The study showed significant correlation between the tumor size $<7 \mathbf{c m}$, old age $>60$, moderately differentiated tumors G2 and treatment outcomes; better locoregional control and better survival rates. On the opposite side poorly differentiated tumors G3, tumor size $>7$ $\mathrm{cm}$ had the worst locoregional control and survival rates. The study also showed significant statistical correlation between treatment modality, locoregional control and survival rates. Patients who were treated by either concommitent chemo-radiotherapy or sequential chemo-radiotherapy had better local control compared to other patients who were treated by radical radiotherapy, and they also had the best survival rates among all the other treatment groups. The average 6 months OAS rates for all studied patients were $60.3 \%$ while 12 months survival rates were $38.8 \%$. The median OAS was 7 months. Conclusions: From the present study, we concluded that concomitant chemo-radiotherapy is the treatment of choice for locally advanced non small cell lung cancer; also we concluded that better performance status and higher hemoglobin levels have better treatment outcome in these cases.

"Corresponding author.

How to cite this paper: Lotayef, M., et al. (2014) A Clinic-Epidemilogical Study of Cases of Locally Advanced Non Small Cell Lung Cancer (NSCLC) That Received Radiotherapy at NCl Cairo in the Period from 2001-2010. Journal of Cancer Therapy, 5, 542-551. http://dx.doi.org/10.4236/jct.2014.56062 


\section{Keywords}

\section{Non Small Cell Lung Cancer, Concomitant Chemo-Radiotherapy}

\section{Introduction}

In the National Cancer Institute (NCI) in Egypt, malignant tumors of the lower respiratory system including the lungs and bronchi constituted $24.16 \%$ of respiratory organ malignancies and $1.54 \%$ of total malignancy with high male predominance [1]-[3].

Radiation therapy plays an important role in the palliation of symptomatic intrathoracic disease. Such symptoms include dyspnea, cough, hemoptysis, and/or chest pain. Common schemes include $10 \mathrm{~Gy}$ in a single fraction, $17 \mathrm{~Gy}$ in two fractions, and $30 \mathrm{~Gy}$ in ten fractions. More conventional 5 or 6 weeks courses have also been used. In general, for symptomatic patients with locally advanced tumors not suitable for curative therapy, abbreviated RT courses have provided similar symptom control and survival compared to more protracted regimens. Regarding relation between RTH and chemo, the superiority of concurrent chemotherapy with radiation therapy compared with sequential chemotherapy followed by irradiation was conclusively demonstrated in large multicenter trials [2] [3].

\section{Patients and Methods}

This is a retrospective study of patients with primary locally advanced NSCLC diagnosed between 2001 and 2010 at the radiotherapy department, National Cancer Institute, Cairo University, Egypt; it included 121 patients who were properly staged. In all patients with complete file data we studied the clinic-epidemiological characteristics of the patients, analyze the prognostic factors and also we analyzed the results of different treatment modalities for local control and their effect on overall survival (OAS).

\section{Statistical Analysis}

The data was summarized by descriptive statistics [i.e., mean, standard deviation (SD), frequencies]. Mean values and standard deviation were compared using simple t test (2 variables). Percentages were compared using Chi-square test or Fisher's exact test. Logistic regression was used whenever the dependant factor was binary in nature (e.g. yes or no) during multivariate analysis. Kaplan-Meier test was used for predictive survival rates. The software used on the analysis was (Version 15; SPSS Institute, Cary, NC, USA, Graph pad instat 2008) and a Pvalue less than 0.05 was considered to be statistically significant.

For all patients, overall survival was calculated starting from date of presentation to the date of death and was also correlated with different prognostic factors.

\section{Results}

The study included 121 patients who were properly staged. Patients who didn’t have proper initial staging or pre-treatment evaluation were excluded.

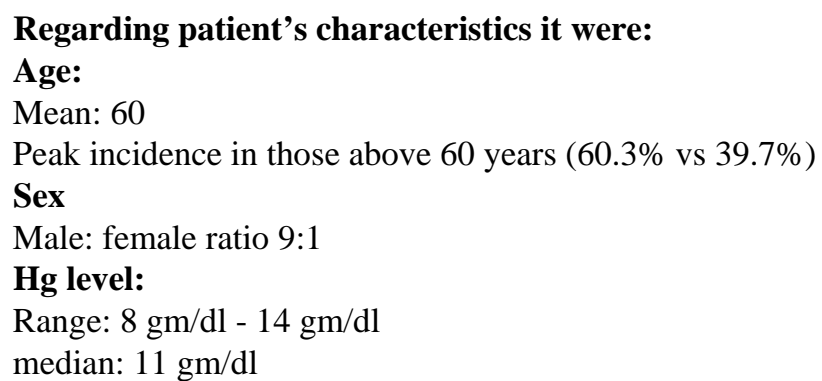

Performance status: Ps according to ECOG performance scale

Ps 3: $45 \%$

Ps 2: $38.8 \%$ 
Ps 1: $14.9 \%$

Ps 0: $0.8 \%$

Main complaint:

Cough: $57 \%$

Dyspnea: $16.6 \%$

Chest pain: $13.2 \%$

Hemoptysis: $13.2 \%$

Type of biopsy:

Bronchoscopic biopsy 51.2\%

CT guided biopsy 33.9\%

FNAC $14.9 \%$

Histopathology:

Squamous cell carcinoma 51.2\%

Large cell carcinoma $17.4 \%$

Adenocarcinoma 31.4\%

Grade:

G2 57\%

G3 43\%

T-stage:

T2 28.9\%

T3 62.8\%

T4 8.3\%

N-stage:

N0 $5.8 \%$

N1 7.4\%

N2 $63.6 \%$

N3 23.2\%

Stage grouping:

IIB $1.7 \%$

IIIA $70.2 \%$

IIIB 28.1\%

Treatment:

Radical treatment: $\mathbf{5 5 . 4 \%}$

Radical radiotherapy $4.1 \%$

Concomitant chemo-radiotherapy 23.1\%

Sequential CTH and RTH 28.2\%

Palliative treatment: $\mathbf{4 4 . 6 \%}$

Palliative radiotherapy

Technique:

2D $87.6 \%$

3D $12.4 \%$

\section{Radiotherapy completion:}

No $16.5 \%$

Yes 83.5\%

On comparing radiotherapy completion with haemoglobin levels we found that most of the patients who completed radiotherapy (91\%) had hemoglobin level $\geq 11 \mathrm{mg} / \mathrm{dl}$ with a P-value which was highly significant $<0.001$, while $91 \%$ of patients who were treated with radical treatment completed their full course of radiotherapy, while $74 \%$ of patients who were treated with palliative treatment completed their prescribed radiotherapy course with a P-value which was significant $=0.012$. Response of the patients to treatment was assessed radiologically and clinically. Fifty one patients had partial response (42\%), forty seven patients were stable (38.8\%) and eight patients had progressive disease (6.6\%) none of the patients achieved complete response.

Regarding distant metastases only 17 patients had distant metastases which were diagnosed during or after finishing their treatment course (14\%). Nine patients had brain metastases while eight patients had bone metas- 
tases (Table 1).

The 6 months and the 12 months overall survival were calculated for all patients and for the different prognostic factors separately and then for each group according to the type of treatment they received. In all groups the 6 months overall survival was $60.3 \%$ and the 12 months overall survival was $38.8 \%$.

Younger patients with locally advanced non small cell lung cancer with age $\leq 60$ showed higher overall survival compared to older patients with age $>60(\mathrm{P}-$ Value $=0.038)($ Figure 1$)$.

Patients with performance status 0 and 1 showed significantly higher overall survival with average survival of 17 months compared with those with performance status 2 and 3 who had an average survival of 7 months. (P-value < 0.001) (Figure 2).

Survival rate was significantly higher among patients with grade 2 than grade 3 tumors; 12 months survival rate was $43.5 \%$ for grade 2 tumors, $32.7 \%$ for grade 3 tumors (P-value $<0.001$ ) (Figure 3 ).

Table 1. Local response compared to different prognostic factors.

\begin{tabular}{|c|c|c|c|c|c|}
\hline Characteristics & Number & Partial response & Stable & Progressive & P-value \\
\hline Over all & 106 & 51 & 47 & 8 & \\
\hline \multicolumn{6}{|l|}{ Age } \\
\hline$\leq 60$ & 44 & $24(54.5 \%)$ & $16(36.4 \%)$ & $4(9.1 \%)$ & \multirow{2}{*}{0.304} \\
\hline$>60$ & 62 & 27 (43.6\%) & $31(50.0 \%)$ & $4(6.5 \%)$ & \\
\hline \multicolumn{6}{|l|}{ Performance Status } \\
\hline $0 \& 1$ & 19 & $13(68.4 \%)$ & $6(31.6 \%)$ & $0(0.0 \%)$ & \multirow{2}{*}{0.092} \\
\hline $2 \& 3$ & 87 & 38 (43.7) & $41(47.1 \%)$ & $8(9.2 \%)$ & \\
\hline \multicolumn{6}{|l|}{ Pathology } \\
\hline Squamous cell carcinoma & 56 & $21(37.5 \%)$ & $30(53.6 \%)$ & 5 (8.9\%) & \multirow{3}{*}{0.230} \\
\hline Adenoc arcinoma & 37 & $23(62.2 \%)$ & $12(32.4 \%)$ & $2(5.4 \%)$ & \\
\hline Large cell carcinoma & 13 & $7(53.8 \%)$ & $5(38.5 \%)$ & $1(7.7 \%)$ & \\
\hline \multicolumn{6}{|l|}{ Grade } \\
\hline G2 & 59 & $31(52.5 \%)$ & $27(45.8 \%)$ & $1(1.7 \%)$ & \multirow{2}{*}{0.039} \\
\hline G3 & 47 & $20(42.6 \%)$ & $20(42.6 \%)$ & $7(14.9 \%)$ & \\
\hline \multicolumn{6}{|l|}{ T-stage } \\
\hline $\mathrm{T} 2$ & 31 & 19 (61.3\%) & $9(29.0 \%)$ & $3(9.7 \%)$ & \multirow{3}{*}{0.109} \\
\hline $\mathrm{T} 3$ & 66 & 30 (45.5\%) & $31(47.0 \%)$ & $5(7.6 \%)$ & \\
\hline $\mathrm{T} 4$ & 9 & $2(22.2 \%)$ & $7(77.8 \%)$ & $0(0.0 \%)$ & \\
\hline \multicolumn{6}{|l|}{ Radical treatment type $(62 / 106)$} \\
\hline Radical radiotherapy & 2 & $1(50.0 \%)$ & $1(50.0 \%)$ & $0(0.0 \%)$ & \multirow{3}{*}{0.324} \\
\hline Concomitant chemo-radiotherpy & 28 & $22(78.6 \%)$ & $6(21.4 \%)$ & $0(0.0 \%)$ & \\
\hline Sequential chemo-radiotherpy & 32 & 19 (59.4\%) & $10(31.2 \%)$ & $3(9.4 \%)$ & \\
\hline \multicolumn{6}{|c|}{ Treatment type (Radical vs. Palliative) } \\
\hline Palliative treatment & 44 & $9(20.5 \%)$ & $30(68.2 \%)$ & $5(11.4 \%)$ & \multirow{2}{*}{$<0.001$} \\
\hline Radical treatment & 62 & $42(67.7 \%)$ & $17(27.4 \%)$ & $3(4.8 \%)$ & \\
\hline \multicolumn{6}{|l|}{ Hemoglobin } \\
\hline$<11 \mathrm{mg} / \mathrm{dl}$ & 26 & $6(23.1 \%)$ & $16(61.5 \%)$ & $4(15.4 \%)$ & \multirow{2}{*}{0.008} \\
\hline$\geq 11 \mathrm{mg} / \mathrm{dl}$ & 80 & $45(56.2 \%)$ & $31(38.8 \%)$ & $4(5.0 \%)$ & \\
\hline \multicolumn{6}{|l|}{ Radiotherapy technique } \\
\hline $2 \mathrm{D}$ & 91 & $42(46.2 \%)$ & $41(45.1 \%)$ & $8(8.8 \%)$ & \multirow{2}{*}{0.386} \\
\hline $3 \mathrm{D}$ & 15 & $9(60 \%)$ & $6(40 \%)$ & $0(0 \%)$ & \\
\hline \multicolumn{6}{|l|}{ Mass size } \\
\hline$<7 \mathrm{~cm}$ & 41 & $28(68.3 \%)$ & $10(24.4 \%)$ & $3(7.3 \%)$ & \multirow{2}{*}{0.002} \\
\hline$>7 \mathrm{~cm}$ & 65 & 23 (35.4\%) & 37 (56.9\%) & $5(7.7 \%)$ & \\
\hline
\end{tabular}




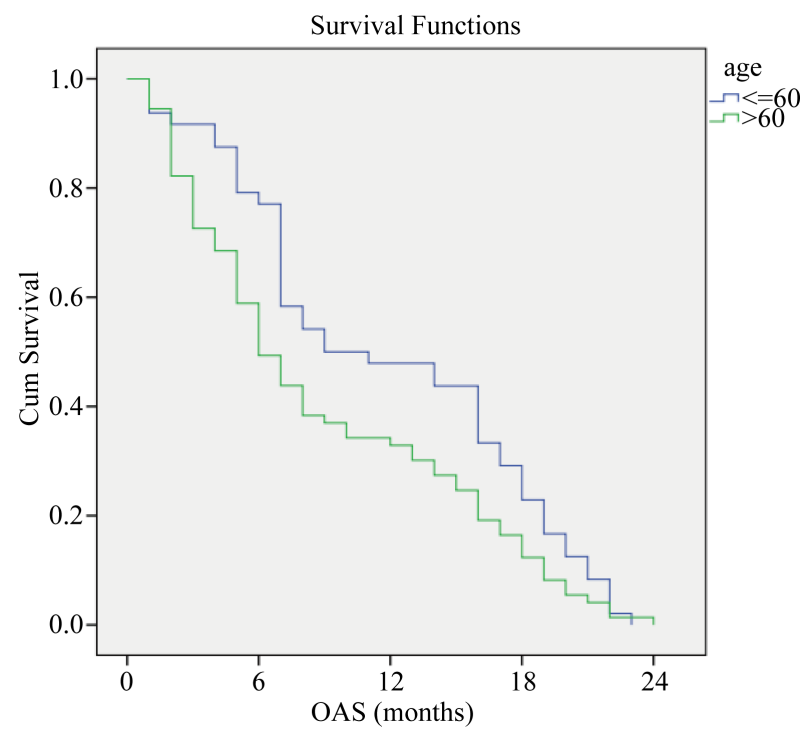

Figure 1. Overall survival compared to age.

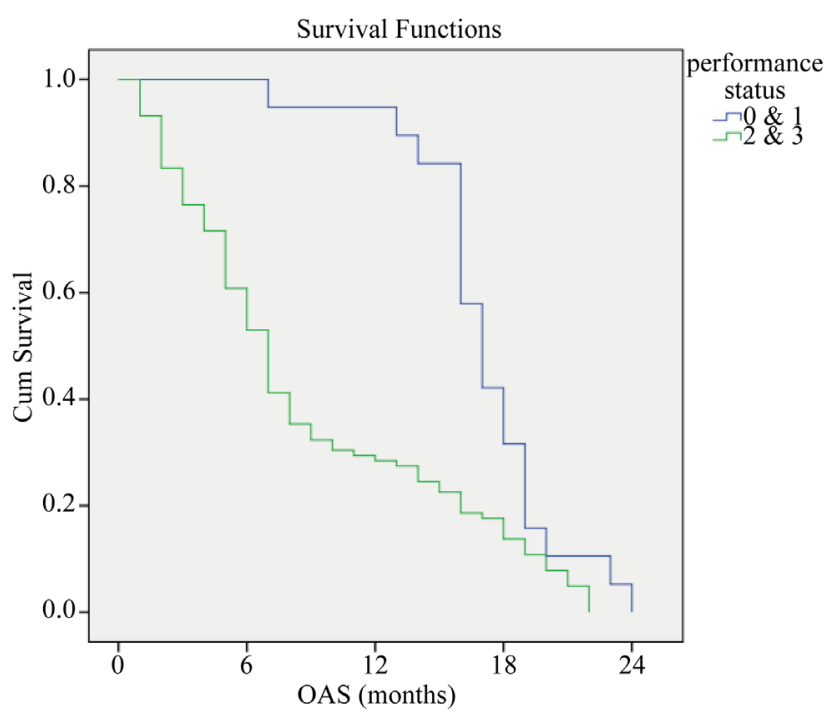

Figure 2. Overall survival compared to performance status.

Survival rate among patients with hemoglobin equal or more than $11 \mathrm{mg} / \mathrm{dl}$ was higher than patients with hemoglobin less than $11 \mathrm{mg} / \mathrm{dl}$ (P-value < 0.001) (Figure 4).

Survival rate was higher among patients with mass size less than or equal $7 \mathrm{~cm}$ compared with patients with mass size more than $7 \mathrm{~cm}$ (P-value < 0.001) (Figure 5).

As expected, those who were treated with radical treatment had a better survival rate than those who were treated with palliative radiotherapy (P-value $<0.001$ ) (Figure 6).

In the radical group, survival rate was higher among patients treated with concomitant chemo-radiotherapy the one year survival was (92.9\%) while it was (55.9\%) for those patients who received sequential chemo-radiotherapy and (20\%) for patients received radical radiotherapy only (P-value $=0.001)$ (Figure 7).

Finally patients who had partial response had higher survival rate than those patients with stable response (P-value < 0.001) (Figure 8).

\section{Discussion}

In the current study most of patients had positive history for smoking (87.6\%) while only (12.4\%) were non- 


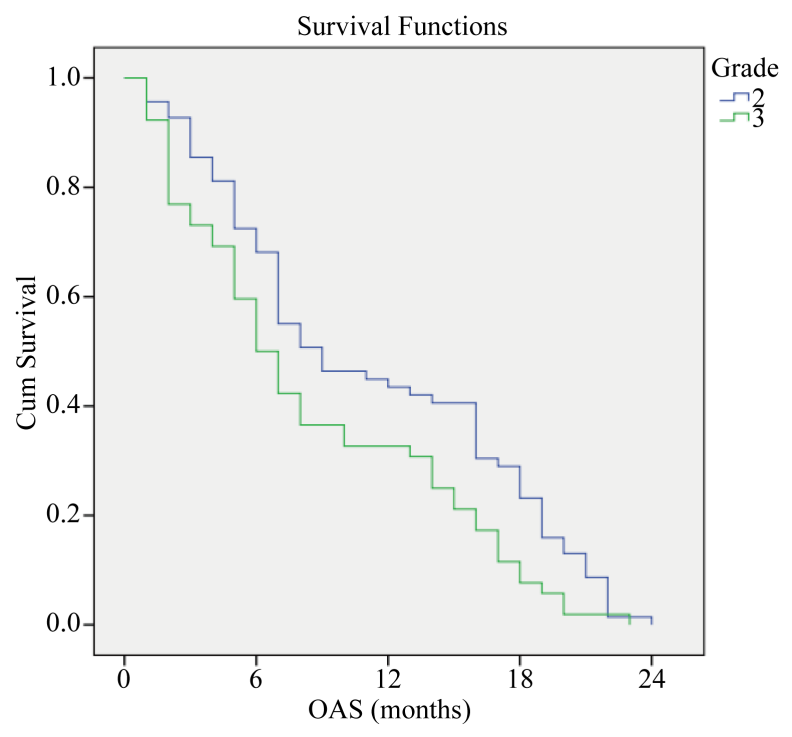

Figure 3. Overall survival compared to tumor grade.

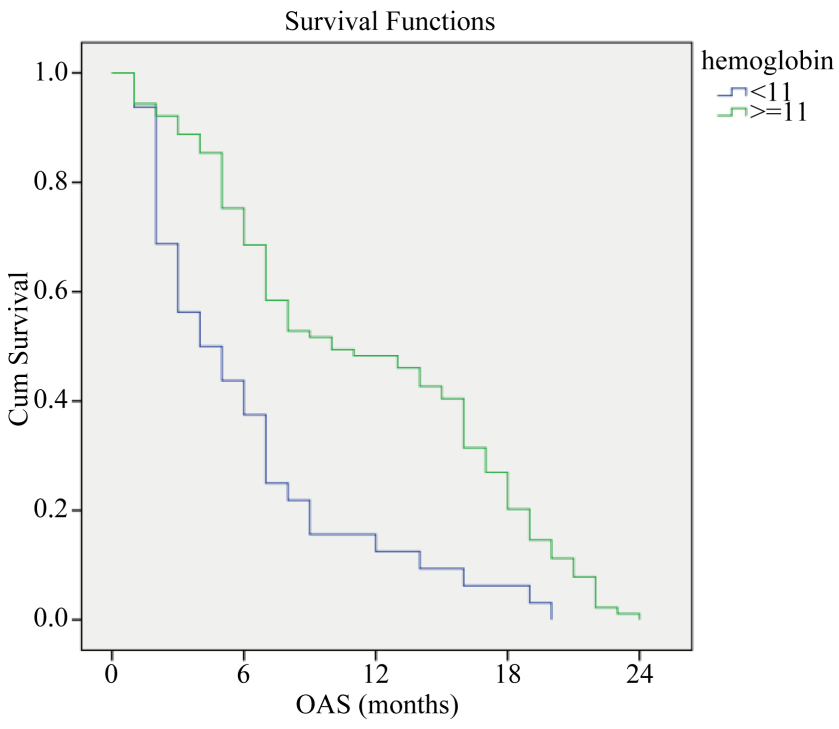

Figure 4. Overall survival compared to hemoglobin level.

smokers also Ries, L.A.G., et al., 2006 found that 90\% of lung cancer is associated with cigarette smoking [4].

In the current study the most common histopathological type was squamous cell carcinoma (51.2\%), while (31.4\%) of the patients were diagnosed as adenocarcinoma while in the WHO classification for primary lung cancer they recognizes three major histologic cell types with approximate frequencies as follows: adenocarcinoma (38\%), Squamous cell carcinoma is (20\%) and large cell carcinoma is (5\%) measured by Survilleillance, Epidemiology and End Results (SEER). This difference could be attributed to different habits as smoking (type and quality of tobacco), occupational exposure (Disel fumes) or previous untreated chronic obstructive pulmonary disease which could play a role and need further investigations [5].

In this study we recorded the hemoglobin level for all patients, we found that $73.6 \%$ of patients had hemoglobin level $>11 \mathrm{mg} / \mathrm{dl}$, in spite of their poor general condition; this could be attributed to high $\mathrm{CO}_{2}$ tension which leads to compensatory hyperplasia by bone marrow which leads to elevated hemoglobin level.

Distant metastases were found in $14 \%$ of our patients during or after finishing their treatment course, in a study by Molina et al., 2008 [6], he found that $40 \%$ of NSCLC will present or develop distant metastases during their treatment. The incidence of brain metastases in our study was $6.5 \%$, while in a study of NSCLC epidemi- 


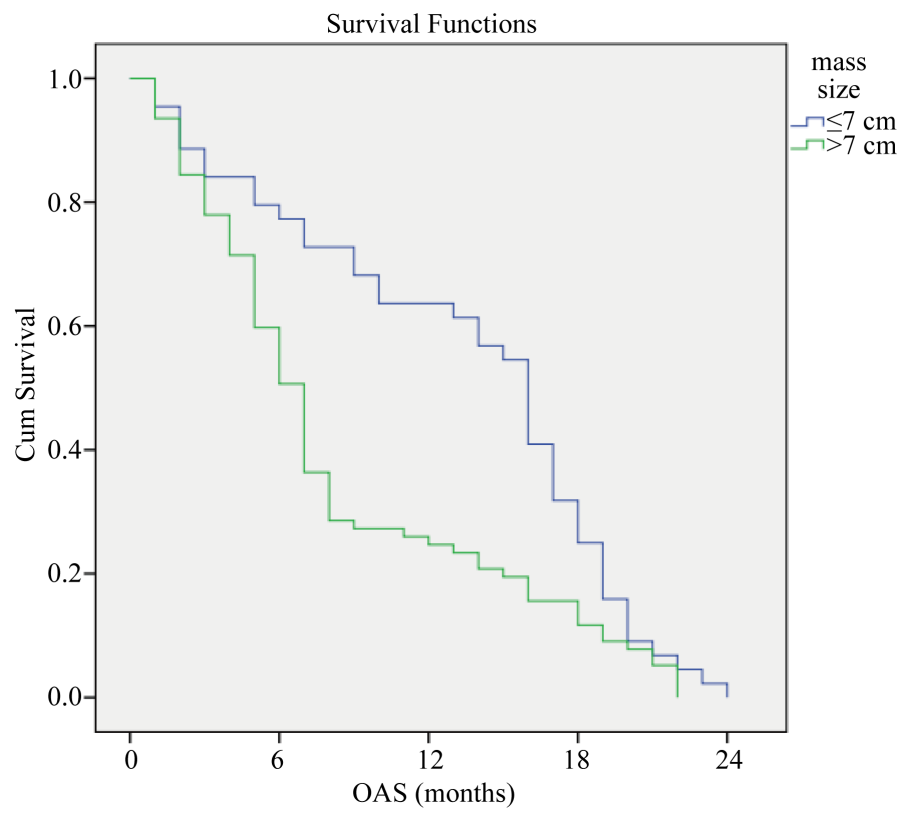

Figure 5. Overall survival compared to mass size.

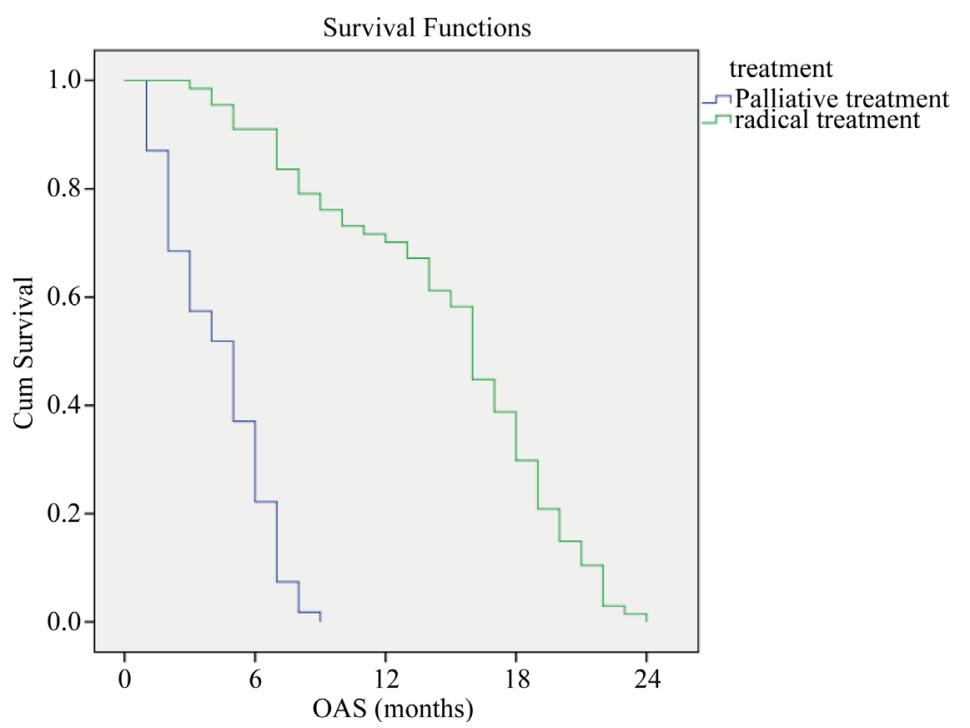

Figure 6. Overall survival compared to purpose of treatment.

ology by Molina et al., 2008 [6], the incidence was 11\%. While In autopsy series done by Galluzzi et al., 1955 [7], the incidence of brain metastases exceeded 25\%. Bone metastases was found in 7.5\% of this study patients, which is comparable to what had been reported by other studies by Molina et al., 2008, and Kuchuka et al., 2013 [6] [8].

In this current study, patients with poor performance status (ECOG 2 \& 3) showed worse local control than those with good performance status (ECOG 0 \& 1). Bezjak, A., et al., 2002 [9] also identified poor performance status (i.e., ECOG PS 2) as a strongly negative prognostic variable with advanced NSCLC. Overall survival was also significantly affected by patients’ performance that patients with good performance status (ECOG 0 \& 1) had better OAS compared to those patients with poor performance status (ECOG $2 \& 3$ ). These results were similar to the results published by Sculier, J.P., et al., 2008 [10].

We found that poorly differentiated tumors (G3) had worse local response than those of moderately differentiated tumors (G2), similar confirmatory results were published by Takies, A., et al., 1988 [11]. 


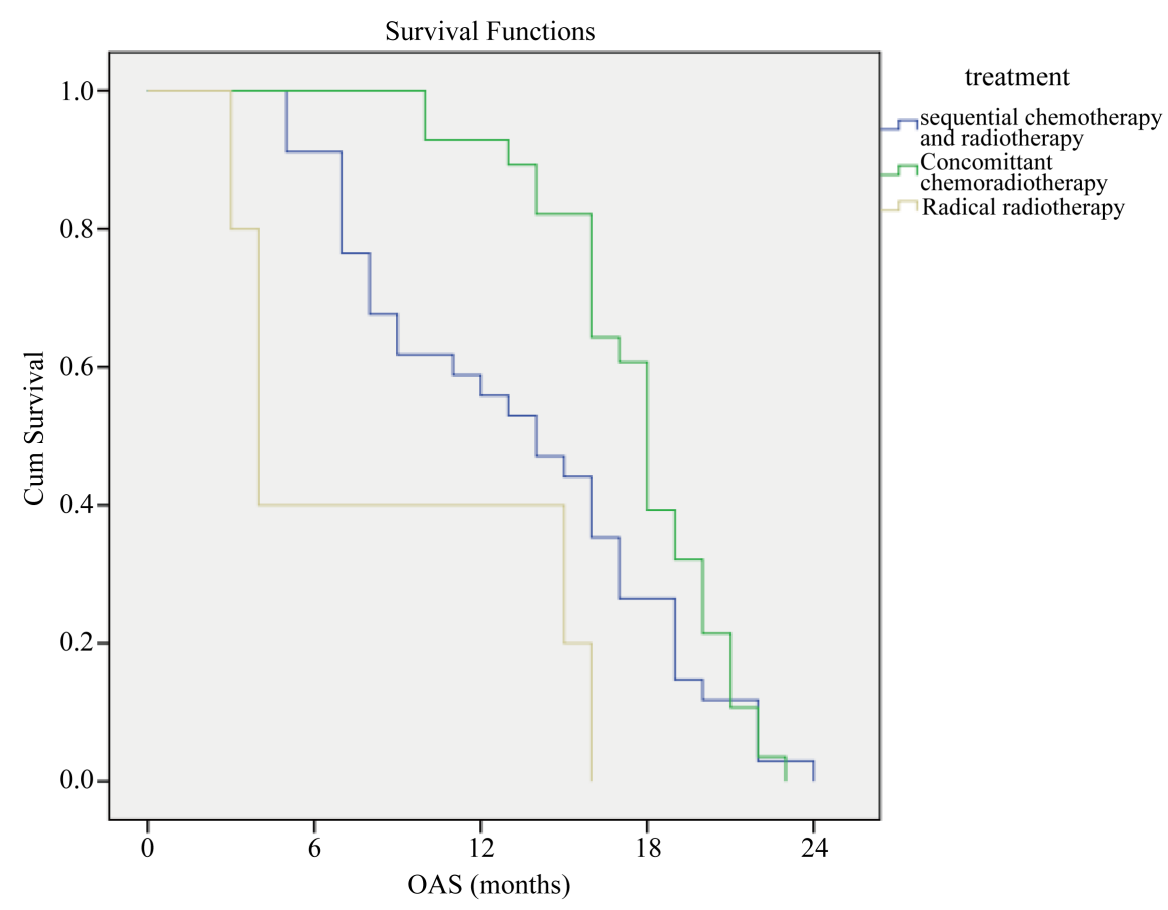

Figure 7. Overall survival compared to type of treatment.

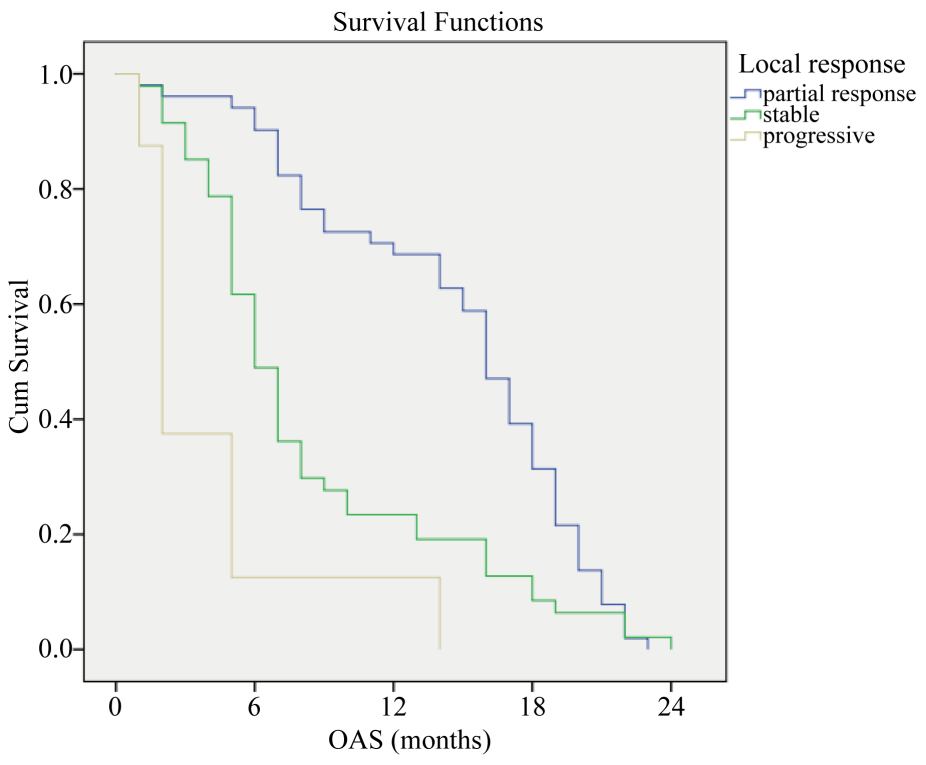

Figure 8. Overall survival compared to type of response.

Most of the patients had poor treatment outcomes as all the patients who were included in this study were diagnosed as locally advanced disease. Confirmatory results were published by (Groome, P.A., et al., 2007) which mentioned that survival decreased progressively with more advanced disease (median of 59 months for patients with stage IA disease compared to four months for those with stage IV disease) [12].

In the current study we found that addition chemotherapy to radiotherapy had improved the OAS compared to radiotherapy alone (survival rate was higher among patients treated with concomitant chemo-radiotherapy the one year survival was $(92.9 \%)$ while it was $(55.9 \%)$ for those patients who received sequential chemo-radiotherapy and (20\%) for patients received radical radiotherapy only (P-value $=0.001)$, this was similar to the results published by Branislav, J., et al., 2012 [13]. 
Also we found that our results is similar to the result published by (Fournel, P., et al., 2005) [14] which confirmed the superiority of concurrent chemotherapy with radiation therapy compared with sequential chemotherapy followed by irradiation. Also similar results were demonstrated by (Zatloukal et al., 2004) [15].

Also Sause, W., et al., 2000 [16] confirmed our data regarding a significant better OAS with sequential chemo-radiotherapy compared to radical radiotherapy. He studied two groups treated with radiotherapy alone or sequential chemo-radiotherapy and he found that median and overall survival were much higher in the sequential chemo-radiotherapy group (23\% with sequential chemo-radiotherapy group compared to $11 \%$ with radiotherapy alone group). These findings were validated by the Radiation Therapy Oncology Group (RTOG) [13] which compared radical radiotherapy (two arms either daily to $60 \mathrm{~Gy}$ or daily to $69.6 \mathrm{~Gy}$ ) vs. sequential chemoradiotherapy arm [13] [16].

The current study showed a significant correlation between local response and OAS, median survival of patients with partial response was 16 months which was higher than those with stable or progressive response (median survival rate was 6 and 2 months respectively). Similar results were published by (Dong et al., 2005) who showed that patients with complete or partial response had improved 4-year overall survival rate compared to patients with no response (stable or progressive disease); $21.1 \%$ vs. $3.3 \%$ [17].

In this study we found a significant correlation between hemoglobin level and overall survival, patients with hemoglobin levels $>11 \mathrm{mg} / \mathrm{dl}$ had median survival of 10 months compared to 4 months for those patients with hemoglobin levels $<11 \mathrm{mg} / \mathrm{dl}$. Julio et al., 2007 had similar results regarding anemia which was associated with poor survival when hemoglobin concentration is less than $12 \mathrm{~g} / \mathrm{dl}$ [18].

\section{Conclusions and Recommendations}

This study matches the published data that support that concomitant chemo-radiotherapy is recommended as the treatment of choice for locally advanced non small cell lung cancer.

Locally advanced non small cell lung cancer is a very aggressive tumor. Most of the patients are presented with advanced late stage disease which is beyond radical treatment. Health education and screening programs are advisable for earlier tumor detection as the tumor stage is the most important prognostic factor for better survival rates.

Further studies on a larger series of patients and introducing new treatment protocols are necessary for final evaluation. Patients should be more involved in clinical trials to achieve the best treatment strategy for this aggressive disease, also we need in the NCI to improve our radiation techniques to decrease as much as possible the radiation induced complications for better treatment outcome.

\section{References}

[1] Mokhtar, N., Gouda, I. and Adel, I. (2004) Cancer Pathology Registry 2003-2004 and Time Trend Analysis.

[2] Curran, W.J., Scott, C., Langer, C., et al. (2003) Long-Term Benefit Is Observed in a Phase III Comparison of Sequential vs Concurrent Chemoradiation for Patients with Unresected Stage III Non Small Cell Lung Cancer: RTOG 9410. Journal of the National Cancer Institute, 22, 621a.

[3] Kong, F.M., Zhao, L. and Hayman, J.A. (2006) The Role of Radiation Therapy in Thoracic Tumors. Hematology/Oncology Clinics of North America, 20, 363-400. http://dx.doi.org/10.1016/j.hoc.2006.01.021

[4] Ries, L.A.G., Harkins, D., Krapcho, M., Mariotto, A., Miller, B.A., Feuer, E.J., Clegg, L., Eisner, M.P., Horner, M.J., Howlader, N., Hayat, M., Hankey, B.F. and Edwards, B.K. (Eds.) (2006) SEER Cancer Statistics Review, 1975-2003. National Cancer Institute. Bethesda.

[5] Adamo, M.B., Johnson, C.H., Ruhl, J.L. and Dickie, L.A. (Eds.) (2011) SEER Program Coding and Staging Manual. National Cancer Institute, Bethesda, NIH Publication Number 11-5581.

[6] Molina, J.R., Yang, P. and Cassivi, S.D. (2008) Non-Small Cell Lung Cancer: Epidemiology, Risk Factors, Treatment, and Survivorship. Mayo Clinic Proceedings, 83, 584-594. http://dx.doi.org/10.4065/83.5.584

[7] Galluzzi, S. and Payne, P.M. (1955) Bronchial Carcinoma: A Statistical Study of 741 Necropsies with Special Reference to the Distribution of Blood-Borne Metastases. British Journal of Cancer, 9, 511. http://dx.doi.org/10.1038/bjc.1955.53

[8] Kuchuk, M., Addison, C.L., Clemons, M., Kuchuk, I. and Wheatley-Price, P. (2013) Incidence and Consequences of Bone Metastases in Lung Cancer Patients. Journal of Bone Oncology, 2, 22-29.

http://dx.doi.org/10.1016/j.jbo.2012.12.004 
[9] Bezjak, A., Dixon, P., Brundage, M., Tu, D., Palmer, M.J., Blood, P., Grafton, C., Lochrin, C., Leong, C., Mulroy, L., Smith, C., Wright, J. and Pater, J.L. (2002) Randomized Phase III Trial of Single Versus Fractionated Thoracic Radiation in the Palliation of Patients with Lung Cancer (NCIC CTG SC.15). International Journal of Radiation Oncology* Biology*Physics, 54, 719-728. http://dx.doi.org/10.1016/S0360-3016(02)02989-9

[10] Sculier, J.P., Chansky, K., Crowley, J.J., et al. (2008) The Impact of Additional Prognostic Factors on Survival and Their Relationship with the Anatomical Extent of Disease Expressed by the 6th Edition of the TNM Classification of Malignant Tumors and the Proposals for the 7th Edition. Journal of Thoracic Oncology, 3, 457.

[11] Takise, A., Kodama, T., Shimosato, Y., Watanabe, S. and Suemasu, K. (1988) Histopathologic Prognostic Factors in Adenocarcinomas of the Peripheral Lung Less Than $2 \mathrm{~cm}$ in Diameter. Cancer, 61, 2083-2088. http://dx.doi.org/10.1002/1097-0142(19880515)61:10<2083::AID-CNCR2820611025>3.0.CO;2-U

[12] Groome, P.A., Bolejack, V., Crowley, J.J., Kennedy, C., Krasnik, M., Sobin, L.H., Goldstraw, P., IASLC International Staging Committee; Cancer Research and Biostatistics, Observers to the Committee and Participating Institutions (2007) The IASLC Lung Cancer Staging Project: Validation of the Proposals for Revision of the T, N, and M Descriptors and Consequent Stage Groupings in the Forthcoming (Seventh) Edition of the TNM Classification of Malignant Tumours. Journal of Thoracic Oncology, 2, 694-705. http://dx.doi.org/10.1097/jto.0b013e31812d05d5

[13] Jeremić, B., Miličić, B., et al. (2012) Concurrent Hyperfractionated Radiation Therapy and Chemotherapy in Locally Advanced (Stage III) Non-Small-Cell Lung Cancer: Single Institution Experience with 600 Patients. International Journal of Radiation Oncology*Biology*Physics, 1157, 1163.

[14] Fournel, P., Robinet, G., Thomas, P., Souquet, P.-J., Léna, H., Vergnenégre, A., Delhoume, J.-Y., Le Treut, J., Silvani, J.-A., Dansin, E., Bozonnat, M.-C., Daurés, J.-P., Mornex, F. and Pérol, M. (2005) Randomized Phase III Trial of Sequential Chemoradiotherapy Compared with Concurrent Chemoradiotherapy in Locally Advanced Nonsmall-Cell Lung Cancer: Groupe Lyon-Saint-Etienne d’OncologieThoracique-Groupe Francais de Pneumo-Cancerologie NPC 95-01 Study. Journal of Clinical Oncology, 23, 5910-5917. http://dx.doi.org/10.1200/JCO.2005.03.070

[15] Zatloukal, P., Petruzelka, L., Zemanova, M., Havel, L., Janku, F., Judas, L., Kubik, A., Krepela, E., Fiala, P. and Pecen, L. (2004) Concurrent versus Sequential Chemoradiotherapy with Cisplatin and Vinorelbine in Locally Advanced Nonsmall Cell Lung Cancer: A Randomized Study. Lung Cancer, 46, 87-98. http://dx.doi.org/10.1016/j.lungcan.2004.03.004

[16] Sause, W., Kolesar, P., Taylor IV, S., Johnson, D., Livingston, R., Komaki, R., Emami, B., Curran Jr., W., Byhardt, R., Dar, A.R. and Turrisi 3rd, A. (2000) Final Results of Phase III Trial in Regionally Advanced Unresectable Non-Small Cell Lung Cancer: Radiation Therapy Oncology Group, Eastern Cooperative Oncology Group, and Southwest Oncology Group. Chest, 117, 358-364. http://dx.doi.org/10.1378/chest.117.2.358

[17] Kim, D.W., Shyr, Y., Chen, H., Akerley, W., Johnson, D.H. and Choy, H. (2005) Response to Combined Modality Therapy Correlates with Survival in Locally Advanced Non-Small-Cell Lung Cancer. International Journal of Radiation Oncology*Biology*Physics, 63, 1029-1036. http://dx.doi.org/10.1016/j.ijrobp.2005.03.055

[18] de Cos Escuín, J.S., Delgado, I.U., Rodríguez, J.C., López, M.J., Vicente, C.D. and Miranda, JA.R. (2007) Stage IIIA and IIIB Non-Small Cell Lung Cancer: Results of Chemotherapy Combined With Radiation Therapy and Analysis of Prognostic Factors. Archivos de Bronconeumología, 43, 358-365. 